\title{
THE EFFECTS OF ELTGOL ON MUCOCILIARY CLEARANCE IN PATIENTS WITH COPD
}

\author{
Jocimar A. Martins, MsC St*, Armèle D. Andrade, PhD\#, Rodrigo S. Assis, MD*, Rovilson Lara, MD* and \\ Verônica F. Parreira, PhD \\ *Arnaldo Gavazza Filho Hospital, Ponte Nova, MG, Brazil \\ ${ }^{\#}$ Federal University of Pernambuco, Recife, PE, Brazil \\ "Federal University of Minas Gerais, Belo Horizonte, MG, Brazil
}

WINNING ABSTRACT: Excessive tracheobronchial secretion is a common complication of chronic obstruction pulmonary disease (COPD) and its presence is associated with lower survival, greater hospitalization and death. Slow expiration with the glottis open in a lateral posture (ELTGOL) is a chest physiotherapy procedure for the removal of lung secretions. Studies which have assessed ELTGOL through pulmonary scintigraphy were not found [1]. The aim this study was to evaluate the effects of ELTGOL on the mucociliary clearance in patients with COPD.

Twelve patients with COPD aged 45 to 75 years were studied. After inhaling $20 \mathrm{mCi}$ of $99 \mathrm{mTC}$-DTPA [2], six posterior static scintigraphy images were taken in intervals of $0,20,40,60,80$ and 120 minutes (figure 1).

The study was carried out in two stages (control and experimental) in a randomized order with a minimum interval of one week between the stages. In the experimental stage, ELTGOL was carried out after the first image. The right lung was studied, comparing the percentage of retention [3] of radioactive aerosol obtained during the control stage with the experimental condition, for each interval studied. The study was approved by the local ethics committee and all patients gave their written consent participate. The t test was used for data analysis with a significance level of $\alpha<0.05$.

As shown in figure 2, significant differences between groups were found between all time intervals.

The present results showed the ELTGOL significantly increased the mucociliary clearance suggesting that ELTGOL is an effective technique to improve secretion removal in patients with COPD.

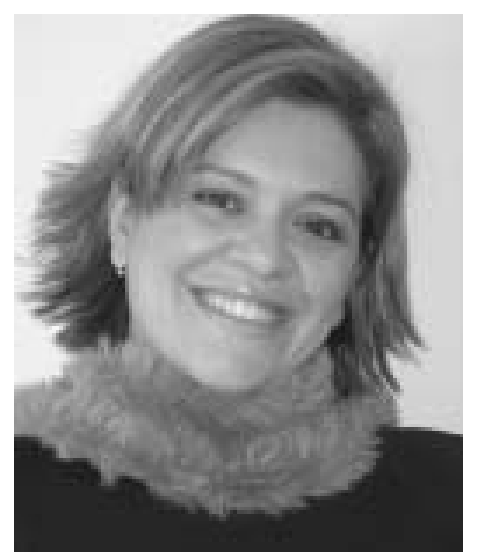

Jocimar A. Martins

Arnaldo Gavazza Filho Hospital, Ponte Nova, MG, Brazil

\section{MY JOB AND THE UNIT IN WHICH I WORK}

I work at Arnaldo Gavazza Filho Hospital, Ponte Nova, MG, Brazil. Our hospital is the regional centre for emergency care, critical care, cardiac surgery, neurological surgery, respiratory care and so on. We are also a big diagnostic centre. I am the head of service of physiotherapy in the hospital. The aim of our service is always to improve patient care. Therefore, we promote self-directed learning and we facilitate continuing professional development to our team. I hope to encourage clinical and practice research in our hospital team, and to use more evidence in our practice. Our study was carried out in the nuclear medicine unit of the hospital, and it was the first study to be performed in association with a university.

\section{MY WINNING POSTER AS PART OF MY RESEARCH}

Our study used pulmonary scintigraphy to evaluate the mucociliary clearance in chronic obstructive pulmonary disease (COPD) hypersecretive patients. These patients were submitted to a chest physiotherapy technique named ELTGOL (from the French: Expiration Lent Totale avec la Glotte Ouverte in infraLateral), proposed by POSTIAUX et al. [4], a Belgian group; the results were compared with a control group. Scintigraphy is a gold standard but is an expensive tool with which to evaluate mucociliary clearance, and the financial support of the hospital to this study was of great importance. The award "Best Poster 2006" was an incentive to us, and I would like to continue performing scientific research.

\section{MY RESEARCH AS PART OF MY WORKING GROUP/ RESEARCH TEAM}

I am presently a Masters student at the Federal University of Minas Gerais, Brazil. I am part of team of the Physical Therapy Department lead by Prof. Verônica Franco Parreira, PhD, and Prof. Raquel Britto, PhD. In our laboratory at the Federal University of Minas Gerais, our team has been performing a number of studies to verify the role of physiotherapy techniques used to prevent or treat respiratory disorders. It can be useful to patients with excessive tracheobronchial secretions or showing decreased lung ventilation as those in post-operative care. With this goal in mind, we are investigating breathing pattern, thoracoabdominal motion, pulmonary volumes and capacities, and also mucociliary clearance in healthy subjects or patients. These variables have been 


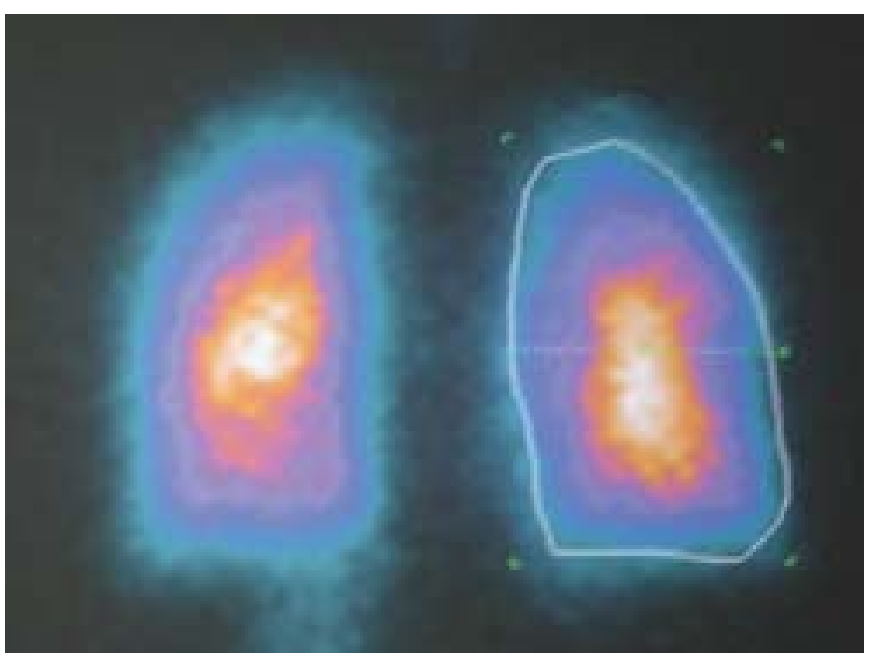

FIGURE 1. Scintigraphy image.

analysed during the use of incentive spirometers, positive expiratory pressure devices or the manual manoeuvre named ELTGOL. Evidence-based physiotherapy is an important part of our current practice. Our leader assists her students in becoming better physiotherapists through the use of evidencebased techniques.

I am also part of the team of directors of SOBRAFIR (the Brazilian Society of Respiratory Physiotherapy). I am the present scientific coordinator of our state (SOBRAFIR - Regional Minas Gerais); we work to promote scientific knowledge, with the aim of a better quality of respiratory physiotherapy.

\section{THE IMPACT OF MY WORK ON CLINICAL OR RESEARCH PRACTICE}

Lower respiratory tract infection is related to $65 \%$ of COPD exacerbation. Exacerbations of COPD cause morbidity, hospital admissions and mortality, and strongly influence healthrelated quality of life [5]. Several therapeutic strategies are used to improve mucus clearance in these patients, including techniques of chest physiotherapy. ELTGOL is used in clinical practice to remove secretion from peripheral airways. This technique is a simple manoeuvre, with low costs, and is advantageous in that there is the possibility of it being

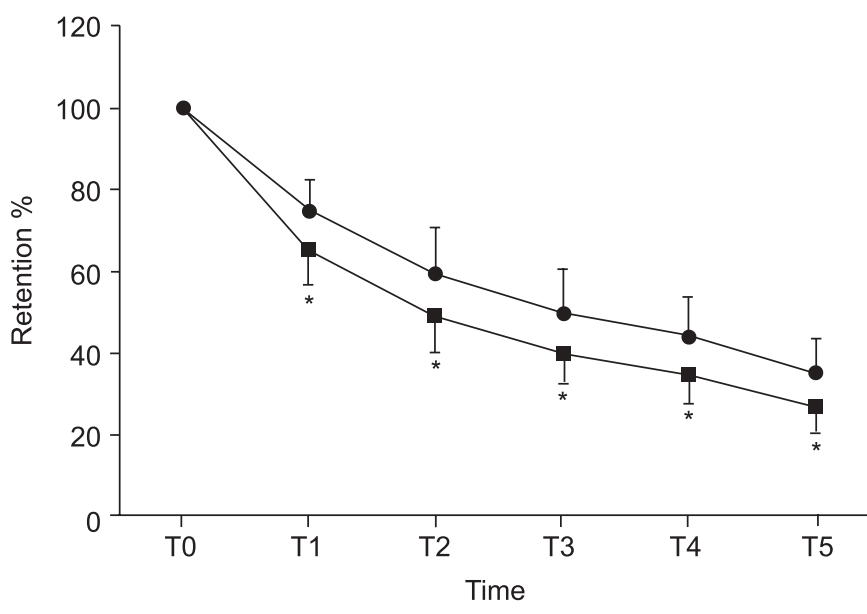

FIGURE 2. Graphic of outcome of $\%$ retention of radioisotopes for control and experimental conditions. $\bullet$ : control; $\mathbf{\square}$ : ELTGOL. *: $p<0.05$.

self-supported after training, without the need of special devices. The application of ELTGOL implies the decreasing of retention secretion in the lungs, which can lead to a reduction of the lower respiratory tract infection episodes.

\section{REFERENCES}

1 Bellone A, Lascioli R, Raschi S, Guzzi L, Adone R. Chest physical therapy in patients with acute exacerbation of chronic bronchitis: effectiveness of three methods. Arch Phys Med Rehabil 2000; 81: 558-560.

2 Lannefors L, Wollmer P. Mucus clearance with three chest physiotherapy regimes in cystic fibrosis: a comparison between postural drainage, PEP and physical exercise. Eur Respir J 1992; 5: 748-753.

3 van der Schans CP. Airway clearance: assessment of techniques. Paediatr Respir Rev 2002; 3: 110-114.

4 Postiaux G, Lens E, Alsteens G, Portelange P. Efficacité de l'expiration lente totale glotte ouverte en décubitus latéral (ELTGOL): sur la toilette en périphérie de l'arbre trachéobronchique. Ann Kinésthér 1990; 17: 87-89.

5 Wedzicha JA, Donaldson GC. Exacerbations of chronic obstructive pulmonary disease. Respir Care 2003; 48: 1204-1213. 